\title{
Incidence and Predictors of Hypertension Among Rural Chinese Adults: Results From Liaoning Province
}

\author{
Zhaoding Sun, MS ${ }^{1}$ \\ Liqiang Zheng, MS ${ }^{1}$ \\ Robert Detrano, $M D, P b D^{2}$ \\ Xingang Zhang, $M D^{1}$ \\ Changlu Xu, MS \\ Jue Li, MD \\ Dayi $H u, M D^{3}$ \\ Yingxian Sun, $M D, P b D^{1}$ \\ 'Department of Cardiology, First Affili- \\ ated Hospital, China Medical University, \\ Shenyang, People's Republic of China \\ ${ }^{2}$ China California Heart Watch, Irvine, \\ California \\ ${ }^{3}$ Heart, Lung and Blood Vessel Center, \\ Tongji University, Shanghai, People's \\ Republic of China
}

\begin{abstract}
OBJECTIVE We wanted to determine the incidence of hypertension and its risk factors among rural Chinese adults.

METHODS A population-based sample of 24,360 rural Chinese adults aged 35 years and older and free from hypertension at baseline was observed from 2004-2006 to 2008. Incident hypertension was defined as a systolic pressure of $140 \mathrm{~mm} \mathrm{Hg}$ or greater, diastolic pressure of $90 \mathrm{~mm} \mathrm{Hg}$ or greater, or current use of antihypertensive medication.
\end{abstract}

RESULTS During a mean follow-up period of 28 months, $29.6 \%$ of men and $23.4 \%$ of women developed hypertension. The age-adjusted incidence was higher in men (12.75 per 100 person-years) than in women (10.04 per 100 person-years). Among men, independent predictors of incident hypertension were baseline age (hazard ratio $[\mathrm{HR}]=1.11 ; 95 \%$ confidence interval $[\mathrm{Cl}], 1.10-1.13$ ), Mongolian ethnicity ( $\mathrm{HR}=1.09 ; 95 \% \mathrm{Cl}, 1.01-1.18)$, use of alcohol, $(\mathrm{HR}=1.14 ; 95 \% \mathrm{Cl}, 1.06$ 1.23), high income vs low income $(\mathrm{HR}=1.11 ; 95 \% \mathrm{Cl}, 1.00-1.22$; and $\mathrm{HR}=1.11$; $95 \% \mathrm{Cl}, 1.03-1.20)$, prehypertension vs normotension $(\mathrm{HR}=1.18 ; 95 \% \mathrm{Cl}, 1.08$ 1.28), overweight and obesity $(\mathrm{HR}=1.28 ; 95 \% \mathrm{Cl}, 1.17-1.40)$, baseline salt intake $(\mathrm{HR}=1.00 ; 95 \% \mathrm{Cl}, 1.00-1.01)$ and family history of hypertension $(\mathrm{HR}=1.14$; $95 \% \mathrm{Cl}, 1.03-1.27)$. With the exception of use of alcohol and mean income, the results were similar for women, except that low physical activity was shown as a risk factors as well. The awareness, treatment, and control rates for newly developed hypertension were $29.9 \%, 19.5 \%$, and $1.5 \%$, respectively.

CONCLUSIONS These data indicate that the incidence of hypertension is high among these rural Chinese adults and that it is associated with many risk factors. Our findings further suggest that most newly developed hypertension cases are not treated. The increases in hypertension are probably related to rapid social changes in our country and may apply to other areas of the developing world. These findings call for urgent improvements in hypertension prevention and control programs in rural China.

Ann Fam Med 2010;8:19-24. doi:10.1370/afm.1018.

\section{INTRODUCTION}

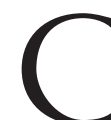
ardiovascular disease, including both stroke and heart disease, is now the leading cause of death among Chinese adults. ${ }^{1}$ Hypertension is an important modifiable risk factor for cardiovascular disease and total mortality in the Chinese population. ${ }^{1}$

Because more than one-half of the Chinese population lives in rural regions, shifts in mortality that are due to cardiovascular disease have enormous public health and economic consequences. Studies published in the 1980s and 1990s suggested that the prevalence and incidence of hypertension in rural China were very low. ${ }^{2}$ During the past 2 decades, however, China in general, and rural China in particular, has been under- 
going rapid social changes. Rural residents periodically commute to urban regions, where they acquire urban and westernized lifestyles and dietary habits. These changes are occurring all over China, but they are particularly pronounced in the northeast and west, where agricultural production is not high and growth of urban centers is accelerating. More recent data suggest a rapid acceleration in the number of cases of hypertension in rural China. ${ }^{3,4}$ Salt consumption has been shown to be higher in northern than in southern China, ${ }^{5}$ and activity levels in northeastern rural China, where Liaoning Province is situated, decreased significantly during the winter. These factors may also contribute to the particularly high prevalence of hypertension in Liaoning Province. ${ }^{3}$

Although we have previously studied and reported on the prevalence of hypertension (number of cases divided by the size of the population), we now report the incidence of hypertension (percentage of new cases appearing each year) in China. Incidence is important in assessing how rapidly a disease is spreading and in determining what measures might be needed in the near and distant future to control the disease. Current data on hypertension incidence in rural China are not available.

\section{METHODS}

\section{Study Design and Study Population}

Study procedures were in accordance with ethical standards of the responsible committee on human experimentation of China Medical University. In 2004 2006, a multistage, random cluster sampling design was used to select a representative sample from the rural population of 45,925 individuals aged 35 years and older from Fuxin, Liaoning Province..$^{3,6}$ In 2008, investigators who had collected contact information on their participants at baseline invited them to return to the clinic for follow-up care. Among the 42,346 individuals invited to return to the clinic for a followup examination, 16,200 had hypertension at baseline and were thus excluded. Of the remaining 26,146 participants, 12,300 men and 12,060 women were free of hypertension at baseline and thus available for the calculation of disease incidence (response rate of 93.2\%).

\section{Baseline Measurement}

Well-trained local doctors made home visits for the baseline examination. Before the survey was undertaken, the research staff were instructed in the purpose of the research and study procedures and trained to administer the survey questionnaire. After this training, only those who scored perfectly on a test could become investigators. During data collection, our inspectors had further instructions and support. Reliability analyses used on data collected by these investigators found high interobserver and intraobserver agreement.

We used a standard questionnaire to collect demographic variables (age, sex, and ethnicity) and socioeconomic data (education level, annual household income); information on alcohol consumption, smoking, physical activity, and hypertension history, including medication usage, was also collected.

Drinking status was assessed by the weekly consumption of beer, wine, and hard liquor converted into grams of alcohol. Current drinking was defined as alcohol consumption of $8 \mathrm{~g} / \mathrm{wk}$ or more. ${ }^{7}$ Current smoking was defined smoking at least 1 cigarette every day for at least 1 year. Family history of hypertension was defined as a diagnosis of hypertension in 1 parent. Body weight and height were measured with participants wearing light clothing and without shoes, and body mass index (BMI) was calculated by weight in kilograms divided by height in square meters.

In rural areas of China, $84 \%$ of consumed salt is added during cooking or as a preservative of foods prepared in the fall for consumption through the spring. The researchers questioned the participants' addition of salt to daily meals, as well as the amount of salt used in salted foods, and then calculated the total salt consumed by the family per year divided by the number of family members to get an estimate of the individual salt intake per year. ${ }^{8}$ Physical activity included occupational and leisure-time physical activity. A detailed description of the methods has been described elsewhere. ${ }^{9}$

A trained and certified observer used an American Heart Association protocol to perform 3 blood pressure measurements with the participant in the sitting position after 5 minutes of rest. Participants were advised to avoid alcohol consumption, cigarette smoking, coffee or tea, and to exercise for at least 30 minutes before these measurements. The research staff used a standardized electronic sphygmomanometer (HEM-741C; Omron, Tokyo, Japan) and 1 of 4 cuff sizes (pediatric, regular adult, large, or thigh) based on arm circumference. We used the Joint National Committee on High Blood Pressure -7 (JNC-7) criteria $^{10}$ to define prehypertension (systolic blood pressure between 120 and $139 \mathrm{~mm} \mathrm{Hg}$ or diastolic blood pressure between 80 and $89 \mathrm{~mm} \mathrm{Hg}$ ) and hypertension (systolic blood pressure of $140 \mathrm{~mm}$ $\mathrm{Hg}$ or greater, diastolic blood pressure of $90 \mathrm{~mm} \mathrm{Hg}$ or greater, or self-reported current treatment for hypertension with antihypertensive medication). ${ }^{4}$ We defined hypertension awareness as a self-report of a health professional's diagnosis, treatment as the current use of a prescription medication for hypertension management, and control as a current mean systolic blood pressure of less than $140 \mathrm{~mm} \mathrm{Hg}$ and an mean diastolic blood pressure of less than $90 \mathrm{~mm} \mathrm{Hg}{ }^{4}$ 


\section{Follow-up Data Collection}

The follow-up examination was conducted from January 2008 to June 2008 among participants who were 35 years of age or older at baseline. Three blood pressure measurements were taken according to a protocol identical to that of the baseline examination, and use of antihypertensive medications was assessed by a standard questionnaire. Incident hypertension was defined as a mean systolic blood pressure of $140 \mathrm{~mm} \mathrm{Hg}$ or greater or diastolic blood pressure of $9 \mathrm{~mm}$ $\mathrm{Hg}$ or greater, or use of antihypertensive medication in the previous 2 weeks at the follow-up examination.

\section{Statistical Analysis}

Baseline characteristics were compared between participants by sex using $t$ tests for continuous variables and $\chi^{2}$ tests for categorical variables. Cumulative incidence of hypertension by sex and age was computed using a simple frequency variable as the number of new hypertension patients during the follow-up period divided by the size of the study population at baseline; sex differences were assessed using a $\chi^{2}$ test. Age-adjusted incidence rates (per 100 person-years) and 95\% confidence intervals (CIs) were estimated using the direct method. To evaluate the hazard risk of hypertension, we used a Cox proportional hazards model, which included age, ethnicity, annual mean income, physical activity, BMI, family history of hypertension, salt intake, smoking, and drinking habits in the model. All analyses were performed with SPSS statistical software, version 12.0 (Statistical Package for the Social Sciences, SPSS Inc, Chicago, Illinois). $P<.05$ was accepted as indicating statistical significance.

\section{RESULTS}

The mean age of the study sample at baseline was 48.21 (SD 10.36) years for men and 47.86 (SD 10.30) years for women. The overall follow-up rate was $93.2 \%$ and the mean follow-up time was 28 months. Men were slightly older than women and were more likely to have graduated from high school, to be more physically active, to have a higher income status, to have a family history of hypertension, and to be a current smoker or drinker (Table 1). The men also had higher blood pressures.

During the follow-up period, $29.6 \%(n=3,639)$ of men and $23.4 \%(n=2,819)$ of women developed incident hypertension (Table 2). Most new cases of hypertension had not been previously diagnosed (70.1\%), and
Table 1. Baseline Characteristics of Study Participants

\begin{tabular}{|c|c|c|c|}
\hline Risk Factor & $\begin{array}{c}\text { Men } \\
(n=12,300)\end{array}$ & $\begin{array}{c}\text { Women } \\
(n=12,060)\end{array}$ & $\begin{array}{c}P \\
\text { Value }\end{array}$ \\
\hline Age, mean (SD), y & $48.21(10.36)$ & $47.86(10.30)$ & .008 \\
\hline Mongolian, \% & 18.0 & 19.4 & .014 \\
\hline High school education, $\%$ & 6.3 & 4.8 & $<.001$ \\
\hline Income, \% & & & .023 \\
\hline Income $1,<¥ 1,000 / y$ & 33.5 & 34.6 & \\
\hline Income $2, ¥ 1,000$ - $¥ 1,500 / y$ & 12.8 & 13.5 & \\
\hline Income $3, ¥ 1,500-¥ 2,000 / y$ & 15.1 & 15.1 & \\
\hline Income $4,>¥ 2,000 / y$ & 38.6 & 36.9 & \\
\hline Physical activity, \% & & & $<.001$ \\
\hline Low & 20.6 & 28 & \\
\hline Moderate & 45.5 & 45.4 & \\
\hline High & 33.9 & 26.6 & \\
\hline Current smoker, \% & 66.9 & 14.2 & $<.001$ \\
\hline Current drinker, \% & 56.0 & 4.8 & $<.001$ \\
\hline Family history of hypertension, \% & 11.0 & 8.1 & $<.001$ \\
\hline Systolic BP, mean (SD), mm Hg & $122.90(10.06)$ & $119.37(11.35)$ & $<.001$ \\
\hline Diastolic BP, mean (SD), mm Hg & $76.86(7.24)$ & $75.26(7.75)$ & $<.001$ \\
\hline Prehypertension, \% & 77.1 & 64.1 & $<.001$ \\
\hline BMI, mean (SD), kg/m² & $22.89(2.66)$ & $23.12(3.05)$ & $<.001$ \\
\hline Salt intake, mean (SD), g/d & $15.61(12.55)$ & $15.29(12.16)$ & .043 \\
\hline
\end{tabular}

Table 2. Cumulative Incidence of Hypertension by Sex and Age-Group Among Rural Chinese

\begin{tabular}{|c|c|c|c|c|}
\hline \multirow[b]{2}{*}{ Characteristic } & \multicolumn{2}{|c|}{ Men } & \multicolumn{2}{|c|}{ Women } \\
\hline & $\begin{array}{c}\text { Case } \\
\mathbf{n}\end{array}$ & $\begin{array}{c}\text { Incidence } \\
\%\end{array}$ & $\begin{array}{c}\text { Case } \\
\mathbf{n}\end{array}$ & $\begin{array}{c}\text { Incidence } \\
\%\end{array}$ \\
\hline \multicolumn{5}{|l|}{ Age-group, years } \\
\hline $35-44$ & 1,215 & 22.0 & 884 & 15.8 \\
\hline $45-54$ & 1,202 & 32.2 & 913 & 25.0 \\
\hline $55-64$ & 769 & 37.6 & 625 & 33.3 \\
\hline$>65$ & 453 & 45.2 & 397 & 42.6 \\
\hline$P$ value & & $<.05$ & & $<.05$ \\
\hline \multicolumn{5}{|l|}{ Race } \\
\hline Mongolian & 852 & 38.5 & 717 & 30.7 \\
\hline Han & 2,751 & 27.7 & 2,052 & 21.5 \\
\hline$P$ value & & $<.05$ & & $<.05$ \\
\hline \multicolumn{5}{|c|}{$\begin{array}{l}\text { Baseline blood pressure } \\
\text { status }\end{array}$} \\
\hline Prehypertension & 2,917 & 30.8 & 2,029 & 26.2 \\
\hline Normal & 722 & 25.6 & 790 & 18.3 \\
\hline$P$ value & & $<.05$ & & $<.05$ \\
\hline Total & 3,639 & $29.6^{a}$ & 2,819 & 23.4 \\
\hline
\end{tabular}


Table 3. Age-Adjusted Incidence of Hypertension in Men and Women of Rural China

\begin{tabular}{lcc}
\hline Characteristic & $\begin{array}{c}\text { Men } \\
\text { Incidence per 100/y } \\
(95 \% \mathbf{C I})\end{array}$ & $\begin{array}{c}\text { Women } \\
\text { Incidence per 100/y } \\
(95 \% \mathbf{C I})\end{array}$ \\
\hline Age-group, years & $9.52(9.01-10.04)$ & $6.78(6.36-7.23)$ \\
$35-44$ & $13.80(13.08-14.54)$ & $10.74(10.09-11.42)$ \\
$45-54$ & $16.27(15.23-17.35)$ & $14.45(13.41-15.53)$ \\
$55-64$ & $18.57(17.05-20.17)$ & $17.95(16.37-19.61)$ \\
$>65$ & $<.05$ & $<.05$ \\
P value & $13.24(12.79-13.69)$ & $11.22(10.77-11.69)$ \\
Baseline blood pressure status & $11.08(10.33-11.86)$ & $7.90(7.38-8.45)$ \\
Prehypertension & $12.75(12.74-13.14)$ & $10.04(9.69-10.41)$ \\
$\quad$ Normal & & \\
$\quad$ Total & & \\
\hline Cl $=$ confidence interval. & & \\
\hline
\end{tabular}

Table 4. Adjusted Hazards Ratio for Hypertension in Men and Women of Rural China

\begin{tabular}{|c|c|c|c|c|}
\hline \multirow[b]{2}{*}{ Predictors } & \multicolumn{2}{|l|}{ Men } & \multicolumn{2}{|c|}{ Women } \\
\hline & $\begin{array}{c}\text { Hazard Ratio } \\
(95 \% \mathrm{Cl})\end{array}$ & $\begin{array}{c}P \\
\text { Value }\end{array}$ & $\begin{array}{c}\text { Hazard Ratio } \\
(95 \% \mathrm{Cl})\end{array}$ & $\begin{array}{c}P \\
\text { Value }\end{array}$ \\
\hline Age & $1.11(1.10-1.13)$ & $<.001$ & $1.13(1.11-1.15)$ & $<.001$ \\
\hline \multicolumn{5}{|l|}{ Education } \\
\hline Not high school graduate & 1.00 (reference) & & 1.00 (reference) & \\
\hline High school graduate & $1.00(0.88-1.13)$ & .960 & $0.87(0.73-1.03)$ & .103 \\
\hline \multicolumn{5}{|l|}{ Annual mean income } \\
\hline Income $1,<¥ 1,000 / y$ & 1.00 (reference) & & 1.00 (reference) & \\
\hline Income $2, ¥ 1,000$ - $¥ 1,500 / y$ & $1.03(0.92-1.15)$ & .584 & $0.99(0.88-1.12)$ & .927 \\
\hline Income $3, ¥ 1,500-¥ 2,000 / y$ & $1.10(1.00-1.22)$ & .045 & $1.09(0.98-1.22)$ & .118 \\
\hline Income 4, > $¥ 2,000 / y$ & $1.11(1.03-1.20)$ & .007 & $1.06(0.97-1.16)$ & .183 \\
\hline \multicolumn{5}{|l|}{ Physical activity } \\
\hline High & 1.00 (reference) & & 1.00 (reference) & \\
\hline Moderate & $0.86(0.80-0.92)$ & $<.001$ & $1.04(0.95-1.15)$ & .408 \\
\hline Low & $1.09(0.99-1.21)$ & .079 & $1.45(1.30-1.61)$ & $<.001$ \\
\hline \multicolumn{5}{|l|}{ Ethnicity } \\
\hline Han & 1.00 (reference) & & 1.00 (reference) & \\
\hline Mongolian & $1.09(1.01-1.18)$ & .032 & $1.16(1.06-1.26)$ & .001 \\
\hline \multicolumn{5}{|l|}{ Smoking } \\
\hline Nonsmoker & 1.00 (reference) & & 1.00 (reference) & \\
\hline Current smoker & $1.00(0.93-1.08)$ & .976 & $0.95(0.86-1.06)$ & .375 \\
\hline \multicolumn{5}{|l|}{ Alcohol drinking } \\
\hline Nondrinker & 1.00 (reference) & & 1.00 (reference) & \\
\hline Current drinker & $1.14(1.06-1.23)$ & $<.001$ & $1.12(0.94-1.32)$ & .194 \\
\hline \multicolumn{5}{|l|}{ Body mass index, $\mathrm{kg} / \mathrm{m}^{2}$} \\
\hline$<25$ & 1.00 (reference) & & 1.00 (reference) & \\
\hline$\geq 25$ & $1.28(1.17-1.40)$ & $<.001$ & $1.45(1.33-1.58)$ & $<.001$ \\
\hline \multicolumn{5}{|l|}{ Family history of hypertension } \\
\hline No & 1.00 (reference) & & 1.00 (reference) & \\
\hline Yes & $1.14(1.03-1.27)$ & .013 & $1.39(1.22-1.58)$ & $<.001$ \\
\hline Salt intake, g/d & $1.00(1.00-1.01)$ & .045 & $1.01(1.00-1.01)$ & $<.001$ \\
\hline \multicolumn{5}{|l|}{ Baseline blood pressure status } \\
\hline Normotentive & 1.00 (reference) & & 1.00 (reference) & \\
\hline Prehypertensive & $1.18(1.08-1.28)$ & $<.001$ & $1.25(1.15-1.36)$ & $<.001$ \\
\hline
\end{tabular}

only $19.5 \%$ of incident cases were being treated with antihypertensive medication; only $1.5 \%$ of incident hypertension cases were controlled (on antihypertension medications and blood pressure in normal range). The incidence of hypertension was higher in participants who were older and had higher blood pressures at baseline for both men and women. The incidence of hypertension was also higher in those of Mongolian ethnicity than it was in those of Han ethnicity for both men and women.

The age-adjusted incidence of hypertension was 12.75 per 100 person-years (95\% CI, 12.74-13.14) in men and 10.04 per 100 person-years $(95 \% \mathrm{CI}$, 9.69-10.41) in women. In both sexes, the incidence rates of hypertension increased with age and were higher in men in all age categories (Table 3). Among participants who were classified as having normal blood pressure at baseline, the age-adjusted incidence of hypertension was 11.08 per 100 person-years (95\% CI, 10.33$11.86)$ in men and 7.90 per 100 person-years $(95 \% \mathrm{CI}, 7.38$ $8.45)$ in women. In comparison, the incidence of hypertension among participants with prehypertension was 13.24 per 100 person-years $(95 \% \mathrm{CI}$, 12.79-13.69) in men and 11.22 per 100 person-years $(95 \% \mathrm{CI}$, 10.77-11.69) in women.

The age-adjusted hazard ratio of developing hypertension associated with each risk factor is displayed by sex in Table 4. Among men, independent predictors of incident hypertension were baseline age, Mongolian ethnicity, higher income, alcohol use, prehypertension, overweight and obesity, salt intake per day, and family history of hypertension. Among women, independent predictors of incident hypertension were similar to the men's, with the excep- 
tion of use of alcohol. Mean income and low physical activity were also risk factors for women.

\section{DISCUSSION}

This study documents a high incidence of hypertension in rural Chinese adults, with most of those new cases untreated and uncontrolled. It also identifies a number of modifiable risk factors for development of hypertension in an environment of increasing urbanization and westernization of diet and health behaviors.

Table 5 displays the estimated annual incidence of hypertension in several studies, including the one reported here. Two Chinese studies ${ }^{2,11}$ undertaken between 1980 and 2000 showed the incidence to be between $2.3 \%$ and $5.2 \%$. These studies included urban Beijing, which had an incidence among men of $4.9 \%$ in the late 1980s, and urban Chinese, which had an incidence among women of $3.9 \%$ in the late 1990s. Two western studies, one from Canada ${ }^{12}$ and the Framingham study ${ }^{13}$ from the United States, found an annual hypertension incidence of between 2.6 and 9.3. The highest annual incidence of $9.3 \%$ was for persons who had prehypertension in the 1990s. Our study in rural Liaoning Province shows an annual hypertension incidence of $11.4 \%$, which is higher than that from any of the other studies whose results are reported in Table 5. We can conclude that in the past 2 decades the incidence of hypertension has been accelerating among rural Chinese adults and now even exceeds the incidence in urban Chinese and in most western counties.

In the last decade, the association between sodium chloride and hypertension has been widely studied and confirmed in the fields of epidemiology and genetics. ${ }^{14-16} \mathrm{Li}$ et $\mathrm{al}^{16}{ }^{16}$ in a large-scale, blinded randomized trial in rural China, confirmed that a potassium chloride-containing salt substitute is an effective and acceptable means of blood pressure control. Although our calculated method of salt intake was not precise, results from our analysis also indicated that higher salt intake contributed to the progression of hypertension. In our study, the average salt intake is more than $15 \mathrm{~g} / \mathrm{d}$ in rural China. According to World Health Organization recommendations, sodium chloride consumption should be less than $6 \mathrm{~g} / \mathrm{d}$ for everyone, especially for children and adults. Health promotion and education about reducing salt intake should therefore be strengthened in this specific region.

The incidence of hypertension may vary in different ethnic groups. ${ }^{11-13,17,18}$ Our data highlighted that the incidence of hypertension was higher in the Mongolian population than in the Han population. Mongolian men and women had hazard ratios of 1.089 and 1.159, respectively, for developing hypertension compared
Table 5. Annual Incidence of Hypertension in Prior Chinese Studies and in the United States and Canada.

\begin{tabular}{lccc}
\hline Country & $\begin{array}{c}1980-1990 \\
\%\end{array}$ & $\begin{array}{c}1990-2000 \\
\%\end{array}$ & $\begin{array}{c}\text { After 2000 } \\
\%\end{array}$ \\
\hline China & $2.3-5.2$ & 3.7 & - \\
Canada & - & 2.6 & 3.2 \\
United States & - & $4.0-9.3$ & - \\
Current study & - & - & 11.4 \\
\hline
\end{tabular}

with the Han population. Further exploration into the genetic causes of incident hypertension for the rural Chinese and Mongolian populations is needed.

Our study reported that more than $80 \%$ of all cases of incident hypertension were untreated. Surprisingly for us, the hypertension control rate was less than $2 \%$, which is similar to our previous cross-sectional study findings. ${ }^{3}$ The Systolic Hypertension in China Study (Syst-China) found that antihypertensive treatment targeted to achieve systolic blood pressure reductions produced a $38 \%$ reduction in stroke, ${ }_{1}^{19}$ which is more prevalent in China. Given the high rates of stroke in China and the striking reductions in cardiovascular events that result from treatment with antihypertensive medication, the high incidence of untreated and uncontrolled hypertension shown here highlights the critical need for enhanced blood pressure monitoring, treatment, and control programs in this rural region. The difficulty in treating hypertension in rural China is evident in other studies as well. ${ }^{20}$ We believe that a public health strategy involving educational and environmental interventions should be targeted at village doctors and others responsible for primary care in rural areas, as well as at the rural population. Public health measures were successful in China during the period between 1950 and 1980 in reducing the incidence of infectious diseases and improving maternal and infant survival. This approach needs to be applied now for chronic diseases, such as hypertension.

There are several limitations to this study. First, follow-up blood pressure was measured 1 time only, which may have resulted in some participants being classified into blood pressure categories incorrectly. Repeated measurements for hypertension should be encouraged during follow-up in subsequent studies. Second, salt intake was measured based on the total amount of salt consumed by a family over 1 year, which may have caused us to underestimate or overestimate the actual level of salt intake in individual family members and to underestimate the role of salt in progression to incident hypertension. In addition, our study sample included rural adults in Liaoning Province only; we could expect varying results had we sampled rural adults in other Chinese provinces. 
The current study showed that more than 1 in 4 Chinese adults from our population-based sample developed hypertension during the period from 2004 2006 to 2008. In addition, the great majority of cases of incident hypertension were untreated. Other studies in developing countries show increases in the incidence of rural hypertension. ${ }^{21-24}$ These authors have also attributed the increase in rural hypertension to increases in urbanization and westernization in their cultures. Addo et $\mathrm{al}^{25}$ reviewed studies done in Africa and found treatment and control rates that were very low, similar to our own. More recently, Akasheh et al ${ }^{20}$ found a high prevalence of hypertension in mountain regions of southwestern China, where hypertension had previously been reported as rare. ${ }^{26}$ Reviewing the literature thus suggests that the problem of increasing incidence of hypertension is not only countrywide in China but is also a worldwide problem that requires international collaboration for analysis and control.

To read or post commentaries in response to this article, see it online at http://www.annfammed.org/cgi/content/full/8/1/19.

Key words: Hypertension/incidence; rural populations; Chinese

Submitted October 16, 2008; submitted, revised, January 3, 2009; accepted February 23, 2009.

Funding support: Grants from the key technology Research and Development program of Liaoning Province (2003225003).

Acknowledgments: We thank our participants for their enthusiastic participation.

\section{References}

1. He J, Gu D, Wu X, et al. Major causes of death among men and women in China. N Engl J Med. 2005;353(11):1124-1134.

2. Wu X, Huang Z, Stamler J, et al.; The PRC-USA Cardiovascular and Cardiopulmonary Epidemiology Research Group. Changes in average blood pressure and incidence of high blood pressure 1983-1984 to 1987-1988 in four population cohorts in the People's Republic of China. J Hypertens. 1996;14(11):1267-1274.

3. Sun $Z$, Zheng $L$, Wei $Y$, et al. The prevalence of prehypertension and hypertension among rural adults in Liaoning province of China. Clin Cardiol. 2007;30(4):183-187.

4. Gu D, Reynolds K, Wu X, et al; InterASIA Collaborative Group. The International Collaborative Study of Cardiovascular Disease in ASIA. Prevalence, awareness, treatment, and control of hypertension in china. Hypertension. 2002;40(6):920-927.

5. Cheng TO. Effects of fast foods, rising blood pressure and increasing serum cholesterol on cardiovascular disease in china. Am J Cardiol. 2006;97(11):1676-1678.

6. Sun Z, Zheng L, Detrano R, et al. The accelerating epidemic of hypertension among rural Chinese women: results from Liaoning Province. Am J Hypertens. 2008;21(7):784-788.

7. National Institute on Alcohol Abuse and Alcoholism. Health Risks and Benefits of Alcohol Consumption. Tenth Special Report to the US Congress on Alcohol and Health. 2000;1:5-11.

8. Tian HG, Hu G, Dong QN, et al. Dietary sodium and potassium, socioeconomic status and blood pressure in a Chinese population. Appetite. 1996;26(3):235-246.
9. Zhang X, Sun Z, Zhang $X$, et al. Prevalence and associated factors of overweight and obesity in a Chinese rural population. Obesity (Silver Spring). 2008;16(1):168-171.

10. Chobanian AV, Bakris GL, Black HR, et al; National Heart, Lung, and Blood Institute Joint National Committee on Prevention, Detection, Evaluation, and Treatment of High Blood Pressure; National High Blood Pressure Education Program Coordinating Committee. The Seventh Report of the Joint National Committee on Prevention, Detection, Evaluation, and Treatment of High Blood Pressure: the JNC 7 report. JAMA. 2003;289(19):2560-2572.

11. Gu D, Wildman RP, Wu X, et al. Incidence and predictors of hypertension over 8 years among Chinese men and women. J Hypertens. 2007;25(3):517-523.

12. Tu K, Chen Z, Lipscombe LL; Canadian Hypertension Education Program Outcomes Research Taskforce. Prevalence and incidence of hypertension from 1995 to 2005: a population-based study. (MAJ. 2008;178(11):1429-1435.

13. Vasan RS, Larson MG, Leip EP, Kannel WB, Levy D. Assessment of frequency of progression to hypertension in non-hypertensive participants in the Framingham Heart Study: a cohort study. Lancet. 2001;358(9294):1682-1686.

14. Lim PO, Farquharson CA, Shiels $P$, Jung RT, Struthers AD, MacDonald TM. Adverse cardiac effects of salt with fludrocortisone in hypertension. Hypertension. 2001;37(3):856-861.

15. Cheung BM, Ho SP, Cheung AH, Lau CP. Diastolic blood pressure is related to urinary sodium excretion in hypertensive Chinese patients. QJM. 2000;93(3):163-168.

16. Li N, Prescott J, Wu Y, et al; for the China Salt Substitute Study Collaborative Group. The effects of a reduced-sodium, high-potassium salt substitute on food taste and acceptability in rural northern China. Br J Nutr. 2009;101(7):1088-1093.

17. Jimenez-Corona A, Lopez-Ridaura R, Stern MP, Gonzalez-Villalpando C. Risk of progression to hypertension in a low-income Mexican population with prehypertension and normal blood pressure. Am J Hypertens. 2007;20(9):929-936.

18. Chien KL, Hsu HC, Sung FC, Su TC, Chen MF, Lee YT. Incidence of hypertension and risk of cardiovascular events among ethnic Chinese: report from a community-based cohort study in Taiwan. J Hypertens. 2007;25(7):1355-1361.

19. Liu L, Wang JG, Gong L, Liu G, Staessen JA; Systolic Hypertension in China (Syst-China) Collaborative Group. Comparison of active treatment and placebo in older Chinese patients with isolated systolic hypertension. J Hypertens. 1998;16(12 Pt 1):1823-1829.

20. Akasheh A, Wu Y, Li Y, et al. Association of blood pressure with lef ventricular mass in untreated hypertensives in rural Yunnan Province. American J Hypertension. 2009;Apr 23. [Epub ahead of print].

21. Reyes-Gibby CC, Aday LA. Prevalence of and risk factors for hypertension in a rural area of the Philippines. J Community Health. 2000;25(5):389-399.

22. Kusuma YS, Das PK. Hypertension in Orissa, India: a cross-sectional study among some tribal, rural and urban populations. Public Health. 2008;122(10):1120-1123.

23. Das M, Pal S, Ghosh A. Rural urban differences of cardiovascular disease risk factors in adult Asian Indians. Am J Hum Biol. 2008; 20(4):440-445

24. Omuemu VO, Okojie OH, Omuemu CE. Awareness of high blood pressure status, treatment and control in a rural community in Edo State. Niger J Clin Pract. 2007;10(3):208-212.

24. Wu X, Duan X, Gu D, Hao J, Tao S, Fan D. Prevalence of hypertension and its trends in Chinese populations. Int J Cardiol. 1995;52(1): 39-44.

25. Addo J, Smeeth L, Leon DA. Hypertension in sub-saharan Africa: a systematic review. Hypertension. 2007;50(6):1012-1018.

26. He J, Klag MJ, Whelton PK, et al. Migration, blood pressure pattern, and hypertension: the Yi Migrant Study. Am J Epidemiol. 1991;134(10):1085-1101. 